\begin{tabular}{|l|l|l||}
\hline \multicolumn{2}{|c|}{ PublisherInfo } \\
\hline \hline PublisherName & $:$ & BioMed Central \\
\hline \hline PublisherLocation & $:$ & London \\
\hline \hline PublisherImprintName & $:$ & BioMed Central \\
\hline \hline
\end{tabular}

\title{
Neoadjuvant hormonal therapy with anastrozole
}

\begin{tabular}{|l|l|l||}
\hline \multicolumn{2}{|c|}{ ArticleInfo } \\
\hline \hline ArticleID & $:$ & 3724 \\
\hline \hline ArticleDOI & $:$ & $10.1186 /$ bcr-2000-66687 \\
\hline \hline ArticleCitationID & $:$ & 66687 \\
\hline \hline ArticleSequenceNumber & $:$ & 90 \\
\hline \hline ArticleCategory & $:$ & Paper Report \\
\hline \hline ArticleFirstPage & $:$ & 1 \\
\hline \hline ArticleLastPage & $:$ & 4 \\
\hline \hline & & RegistrationDate : 2000-7-26 \\
\hline ArticleHistory & $:$ & OnlineDate \\
\hline \hline ArticleCopyright & $:$ & Current Science Ltd2000-7-26 \\
\hline \hline ArticleGrants & $:$ & \\
\hline \hline ArticleContext & $:$ & 1305822 \\
\hline \hline
\end{tabular}




\section{Caroline Lohrisch, ${ }^{\text {Aff1 }}$}

Aff1 Investigational Drug Branch for Breast Cancer, branch of the EORTC, Brussels

\section{Keywords}

Aromatase inhibitors, locally advanced, neoadjuvant

\section{Introduction}

Thus far, randomized trials have failed to show a survival advantage for neoadjuvant systemic therapy over adjuvant therapy; however, neoadjuvant therapy can effectively reduce the need for mastectomy in locally advanced and large primary breast cancers. Nonsteroidal aromatase inhibitors, including anastrozole, have shown high activity in hormone receptor positive metastatic breast cancer (MBC). Given recent reports (see Aditional Information) its value in high risk primary disease is worth exploring.

\section{Aims}

Two doses of anastrozole were tested for their effect on tumor volume and breast conservation rates in large or locally advanced breast tumors occurring in postmenopausal women.

\section{Comments}

Neoadjuvant chemotherapy and hormonal therapy are effective in reducing tumor size, thus facilitating breast conservation surgery. This small feasibility study shows the efficacy of anastrozole in reducing tumor volume and mastectomy requirements in postmenopausal women with locally advanced and large operable breast tumors. A formal comparison of anastrozole with standard hormonal and/or chemotherapy treatments is warranted to establish the relative value of this hormonal therapy in the neoadjuvant setting. 


\section{Methods}

Postmenopausal women with nonmetastatic large $(>3 \mathrm{~cm})$ or locally advanced breast cancer that was estrogen receptor (ER) rich were randomly assigned to anastrozole (1 or $10 \mathrm{mg} /$ day) for 12 weeks preoperatively in this double blind single center study. No other concurrent anti-tumor therapy was allowed. Tumor volume was assessed clinically (calipers), by mammography and by ultrasound at baseline and weeks 4,8 , and 12 . Week 12 tumor volume by estimated by these methods was compared with actual volume (gross specimen) measured at surgery. The type of surgery required (mastectomy or lumpectomy) was assessed before treatment and surgery. Patients whose tumors progressed on anastrozole proceeded directly to surgery. No formal statistical calculation was used to determine the sample size.

\section{Results}

Twenty-six patients were enrolled and treated: in three, tumor volume was not analysed due to insufficient ER levels for eligibility $(\mathrm{n}=2)$ and drug intolerance (fatigue, depression, headache) leading to withdrawal $(\mathrm{n}=1)$. For the anastrozole $1 \mathrm{mg}$ and $10 \mathrm{mg}$ groups $(\mathrm{n}=12 \mathrm{each})$, mean ages were 74 and 69, T2 (2 cm - $5 \mathrm{~cm}$ primaries) occurred in 11 and 10, and clinical lymph node involvement was evident in two and one patients respectively. No patient progressed on therapy. Median tumor volume reduction from baseline using ultrasound was $80.5 \%$ for the $1 \mathrm{mg}$ dose, $69.9 \%$ for $10 \mathrm{mg}$, and $75.5 \%$ for the combined groups. The median volume assessed by ultrasound was smaller than the gross pathologic volume by $12 \%$. For caliper and mammogram assessments of tumor size, the differences were underestimates of $24 \%$ and $133 \%$, respectively, suggesting that ultrasound is the most accurate clinical measurement tool. After 12 weeks of anastrozole, breast conservation surgery was possible in 15 of the 17 patients for whom mastectomy had been planned. All patients with clinically involved lymph nodes at baseline had pathologically involved nodes, although, in one, nodes became clinically negative.

\section{Discussion}

The results suggest that ultrasound is the most accurate method to follow the tumor clinically. Although this study showed promising clinical activity, the sample size was small and it would have been interesting to include a comparison of pre-treatment and post-treatment histologic characteristics to explore the biomodulating effects of anastrozole. The stage is now set for a randomized comparison of neoadjuvant anastrozole with TAM in a similar patient population and/or comparison of neoadjvuant with adjuvant anastrozole. The advantage of the former design is in being able to compare breast conservation rates in addition to disease-free and overall survival, endpoints which have thus far proven difficult to improve in this high-risk disease. Neoadjuvant anastrozole should be considered experimental at this stage; however, the question arises of whether patients treated with neoadjuvant 
anastrozole should continue with it or use TAM in the adjvuant setting. Randomized comparisons of adjuvant nonsteroidal aromatase inhibitors vs TAM are ongoing and perhaps results will be available by the time a randomized neoadjuvant study with anastrozole has been completed thus providing the answer.

\section{Additional information}

Proceedings of the22nd annual San Antonio Breast Cancer Symposium; Nabholtz et al, Breast Cancer Res Treat 1999, 57:abstract 27

Buzdar AU Jonat W Howell A Jones SE Blomqvist CP Vogel CL Eiermann W Wolter JM Steinberg $M$ Webster A Lee D Anastrozole versus megestrol acetate in the treatment of postmenopausal women with advanced breast carcinoma: results of a survival update based on a combined analysis of data from two mature phase III trials. Arimidex Study Group. Cancer 1998, 83:1142-1152 [Abstract]

\section{References}

1. Dixon JM, Renshaw L, Bellamy C, Stuart M, Hoctin-Boes G, Miller WR: The effects of neoadjuvant anastrozole (Arimidex) on tumor volume in postmenopausal women with breast cancer: a randomized, double-blind, single-center study. Clin Cancer Res. 2000, 6: 2229-2235.

This PDF file was created after publication. 